\title{
Improvement of ex vitro acclimatization of mulberry plantlets by supplement of abscisic acid to the last subculture medium
}

\author{
Yoon Sun Huh $\cdot$ Joung Kwan Lee $\cdot$ Sang Young Nam
}

Received: 7 September 2017 / Revised: 12 October 2017 / Accepted: 12 October 2017

(c) Korean Society for Plant Biotechnology

\begin{abstract}
Mulberry (Morus sp.) of the family Moraceae is very economically important in Asian countries including Korea, because its leaf and fruit have been commercially used in sericulture and horticultural industries. Therefore it is necessary to develop the optimal production system for rapid and cost-effective propagation of mulberry. Our studies focused on establishing an acclimatization method for the successful plantlet production of new cultivar 'Cheongsu' which was transferred ex vitro after in vitro culture. In particular, effect of abscisic acid (ABA) addition into the last subculture medium on plantlet response to subsequent $e x$ vitro transfer and its growth was investigated. During acclimatization, stomatal conductance and transpiration rate of ABA-pretreated plantlets were significantly lower than those of non-treated plantlets. Net photosynthetic rate of ABA-pretreated plantlets decreased after ex vitro transfer but increased after 14 days, and it was mostly higher than that of non-treated plantlets. Moreover, relative water content as well as chlorophyll contents and its ratio were also higher in ABA-pretreated plantlets. On the other hand, proline was considerably higher than in control plantlets. After 1 month of ex vitro transfer, survival rate of ABA-pretreated plantlets was $85.6 \%$, which increased by $29.1 \%$ in comparison with control (56.5\%). More vigorous growth was also observed in ABA-pretreated plantlets. From these results, it was found that application of ABA to the last subculture medium could improve acclimatization and promote survival of mulberry plantlets after ex vitro transfer, inducing water stress tolerance and alleviating abiotic stresses.
\end{abstract}

Keywords Mulberry, Abscisic acid, Ex vitro transfer, Acclimatization, Water stress

Y. S. Huh $(\varangle) \cdot$ J. K. Lee $\cdot$ S. Y. Nam

Horticultural Research Division, Chungcheongbuk-do Agricultural Research and Extension Services, Cheongju, 28130, Korea e-mail: yshuh2@korea.kr

\section{Introduction}

Mulberry (Morus sp.) is an economically important tree grown in India, China, Korea and several Asian countries where its foliage is used as food for silkworms in sericulture industry (Vijayan et al. 2012). It is also commercially valuable in the horticulture, food and cosmetic industries, in particular, its phytochemical and medicinal properties such as antioxidants (Yen et al. 1996) and hypoglycemia compounds (Kelkar et al. 1996) have been widely used as healthcare products. These days it is cultivated for fruit production, which is used for human consumption including jam, jelly, frozen desserts, pulp, juice and wine (Koyuncu 2004). Mulberry fruit is regarded as a traditional medicine for dysentery, constipation and avulsed teeth due to rich phenolic acids and flavonoids (Arfan et al. 2012; Lee and Bae 2011).

Plant micropropagation has been widely applied to agriculture industry for large scale production of economically important and valuable species. But its commercial use is limited in many species due to the low plantlet survival rates during the acclimatization (Pospisilova et al. 2009a, b), which are known to be related to an abnormal morphology, anatomy and physiology under in vitro culture conditions (Dias et al. 2013a). Poor functioning of overall water housekeeping system such as deficient stomatal control and cuticular abnormalities, which is involved in the drastically different vapor pressure between in vitro and ex vitro conditions, can induce the water deficit and plant dehydration during $e x$ vitro transfer and acclimatization. Higher irradiance can also increase the harmful stress and restrict a plantlet growth, resulting in the photoinhibition or generation of reactive oxygen species (ROS). Therefore, the regulation of transpiration and stabilization of water status as well as adequate operation of photosynthetic mechanism are very important for plant survival and its further growth during an adaptation period to the new growing environment (Desjardins et al. 2009; Pospisilova et al. 2009b). 
Abscisic acid (ABA) plays a critical role in many physiological processes of plants including water balance and in the adaptation of plants to stress environments (Finkelstein and Gibson 2002; Hetherington 2001). It is transported via xylem to the shoot, where it regulates transpiration loss of water and leaf growth (Hronkova et al. 2003). Various stresses induce $\mathrm{ABA}$ synthesis and it is considered as a plant stress hormone (Tuteja 2007). Role of abscisic acid on tolerance to abiotic stresses has also been reported when tissue cultured plantlets are transferred directly to the field (Aguilar et al. 2000). It can act as an anti-transpirant during the acclimatization of tissue-cultured plantlets and reduce the relative water loss of the leaves of micropropagated plantlets during transplantation even when non-functional stomata are present (Pospisilova et al. 1999, 2007). Several studies reported that an exogenous ABA addition into the culture medium could reduce the programmed cell death, known as apoptosis, in cultured cells and tissues (Carimi et al. 2003; Pennell and Lamb 1997; Wang et al. 1999). Therefore acclimatization can also be improved by the positive effect of $\mathrm{ABA}$ on chlorophyll contents and other photosynthetic parameters as well as on plant growth.

In these studies, we tried to investigate the effect of an exogenous $\mathrm{ABA}$ addition to the last culture medium on photosynthetic parameters, proline content and survival of mulberry plantlets during acclimatization after $e x$ vitro transfer, and furthermore, to propose the importance of $\mathrm{ABA}$ treatment prior to transplanting for large scale propagation.

\section{Materials and Methods}

Plants and cultivation

Mulberry plantlets (Morus alba L. cv Cheongsu) were cultured

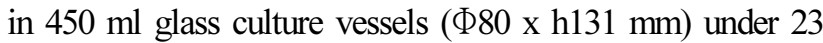
$\pm 1^{\circ} \mathrm{C}$ and $16 \mathrm{~h}$ photoperiod ( $40 \mu \mathrm{mol} \cdot \mathrm{m}^{-2} \cdot \mathrm{s}^{-1}$ light intensity). At the last subculture stage, $10 \mathrm{uM} \mathrm{ABA}$ was added into the medium. Control plants were cultured on the same medium without ABA. After 4 weeks of last subculture, mulberry plantlets $(6 \mathrm{~cm}$ high) were taken out of the culture vessels and washed several times with distilled water to remove traces of medium on plantlet surfaces. Then, they were transferred to pots with a mixture of common horticultural substrates and perlite (1:1), and placed in the acclimatization room, which minimum and maximum air temperatures were kept between 16 and $28^{\circ} \mathrm{C}$, and relative humidity was gradually decreased from 90 to $60 \%$. After acclimatization and hardening phase for 1 month, the general plant growth characteristics including shoot number, length and survival rate were measured. This experiment was designed randomly. Each treatment had ten replicates and was conducted three times.

Determination of relative water content and photosynthetic parameters

Leaves were sampled from mulberry plantlets before ex vitro transfer as well as 1, 2, 3 and 4 hours after ex vitro transfer for calculating their relative water content (RWC). RWC was measured gravimetrically in leaf discs (about $0.5 \mathrm{~cm}^{2}$ ) which were water-saturated by immersing into holes of fully wet polyurethane foam under dark according to Catsky (1960). It was calculated form gradual decrease in fresh mass of initially water-saturated leaves and dry mass.

Net photosynthesis $\left(\mathrm{P}_{\mathrm{N}}\right)$, transpiration rate $(\mathrm{Tr})$, and stomatal conductance $\left(\mathrm{C}_{\mathrm{S}}\right)$ were measured before ex vitro transfer as well as 7, 14, 21 and 28 days after ex vitro transfer using a portable open photosynthesis system (LI-6400, LI-COR, USA). All measurements were taken with leaf temperature maintained at $20^{\circ} \mathrm{C}$, relative humidity between $50 \%$ and $65 \%$, and a leaf to air vapor pressure deficit (VPD) of $0.8 \sim 1.2$ $\mathrm{kPa}$. $\mathrm{CO}_{2}$ concentration within the chamber was maintained at $370 \mu \mathrm{mol} \cdot \mathrm{mol}^{-1}$, and light intensity was maintained at $800 \mu \mathrm{mol} \cdot \mathrm{m}^{-2} \cdot \mathrm{s}^{-1}$.

Measurement of leaf chlorophyll content

Leaves were sampled from mulberry plantlets before ex vitro transfer and at 7, 14, 21, 28 days after ex vitro transfer. Leaf discs (about $0.8 \mathrm{~cm}$ in diameter) were weighted and incubated with $3 \mathrm{ml}$ dimethyl sulfoxide (DMSO) in a test tube at $65^{\circ} \mathrm{C}$ until the tissue became colorless. The absorbance at 664.9 and $648.2 \mathrm{~nm}$ of the DMSO extract was determined with a spectrophotometer (SoftMax Pro, Molecular Device Co., USA), and the chlorophyll a and b concentrations of the leaves were calculated according to Barnes et al. (1992) method.

\section{Proline assay}

Leaves were sampled from mulberry plantlets before ex vitro transfer and at 7, 14, 21, 28 days after ex vitro transfer for proline analysis. Proline content was measured according to methodology described by Bates et al. (1973). $0.2 \mathrm{~g}$ of fresh leaf samples were homogenized in $3 \mathrm{~mL}$ of $3 \%$ aqueous sulphosalicylic acid and the residue was removed by centrifugation at $12,000 \mathrm{~g}$ for $10 \mathrm{~min} .2 \mathrm{~mL}$ of the homogenized 
supernatant was reacted with $1 \mathrm{~mL}$ acid-ninhydrin and $1 \mathrm{~mL}$ of glacial acetic acid for 1 hour at $100^{\circ} \mathrm{C}$, and this reaction was terminated in an ice bath. The reaction mixture was extracted with $2 \mathrm{~mL}$ toluene, mixed vigorously and left at room temperature for $30 \mathrm{~min}$ until separation of the two phases. The chromophore-containing toluene $(1 \mathrm{~mL}$, upper phase) was warmed to room temperature and its optical density was measured at $520 \mathrm{~nm}$ using toluene for a blank. The proline concentration was determined from a standard curve using L-Proline and calculated as umol $\cdot \mathrm{g}^{-1} \mathrm{FW}$.

\section{Statistics}

All analytical experiments were repeated twice. In each experiment a set of 20 plants were used for determination of each parameter. Means and standard error (SE) were calculated using SigmaStat (Windows, version 3.1.).

\section{Results and Discussion}

Effect of ABA on relative water content and photosynthetic parameters during acclimatization of in vitro cultured mulberry plantlets

Figure 1 showed the relative water content and photo- synthetic parameters of mulberry plantlets pretreated with or without $\mathrm{ABA}$ during acclimatization after ex vitro transfer. Relative water content (RWC) was respectively measured in ABA-treated and control plantlets taken out of culture vessels before and after ex vitro transfer. It decreased more slightly in ABA-treated plantlets in comparison with non-treated plantlets, which means that ABA-treated plantlets might be much less dehydrated right after ex vitro transfer. On the contrary, control plantlets showed a steeper reduction of RWC after ex vitro transfer, indicating that these plants might be under a severe water stress conditions. ABA-treated plantlets showed lower stomatal conductance (Cs) and transpiration rate ( $\mathrm{Tr}$ ) than control plantlets, these reduction of $\mathrm{Cs}$ and Tr values means that ABA-pretreated plants exhibited a better water status. But Cs and Tr increased rapidly until 14 days after ex vitro transfer and decreased gradually afterward in control plantlets. Net photosynthetic rate (Pn) of ABA-treated plantlets was rather higher, and its drastic reduction was not observed. On the other hand, in control plantlet, it fell down considerably until 14 days after ex vitro transfer and increased since then. From these results, ABA pretreatment might reduce $\mathrm{Cs}$ and $\mathrm{Tr}$, induce higher $\mathrm{Pn}$, and strengthen adaptation capacity of plantlets after ex vitro transfer.

During acclimatization, plantlets are subjected to various stresses in response to changes in ex vitro environmental conditions, due to impaired stomata function and reduced

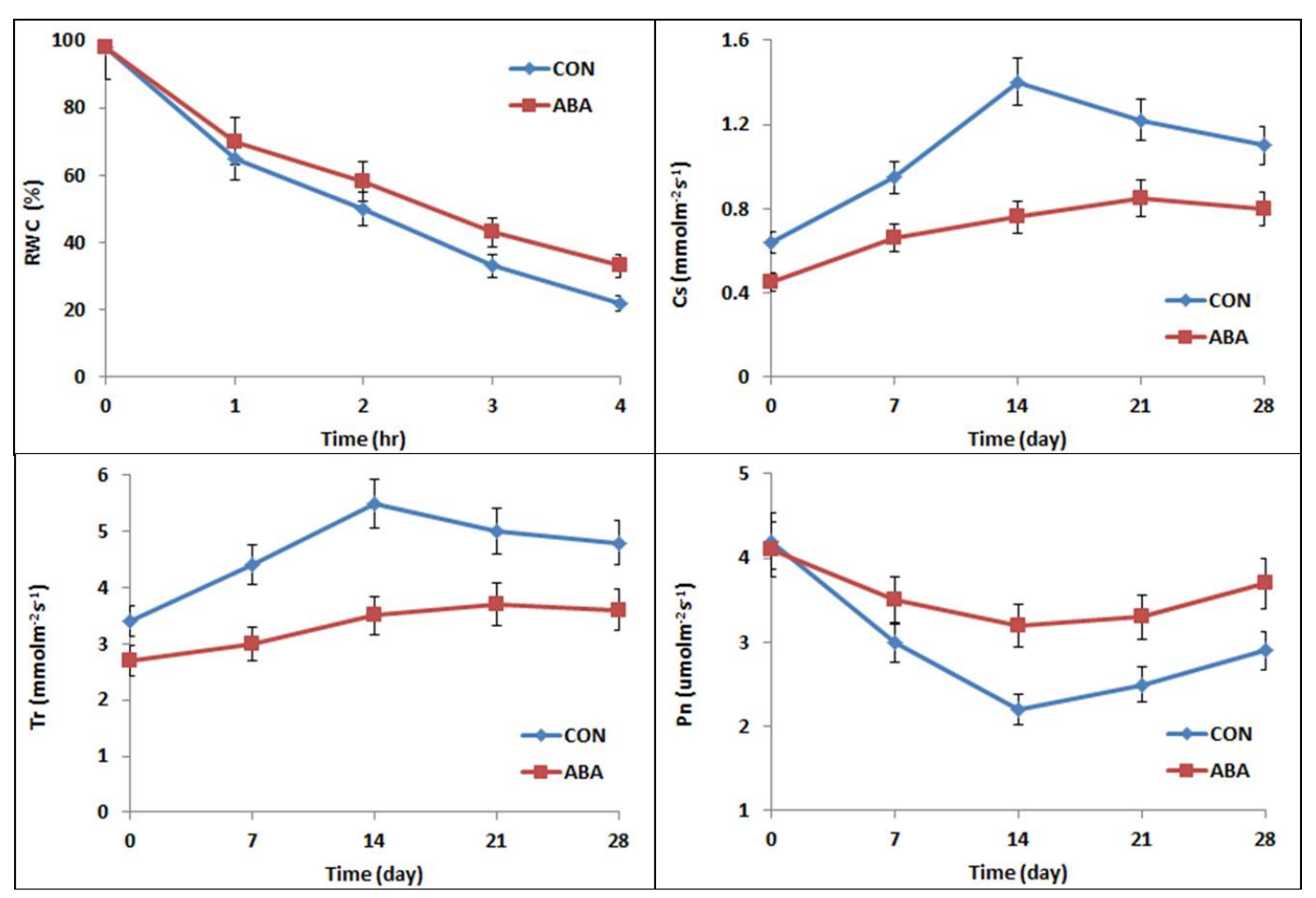

Fig. 1 Relative water content (RWC), stomatal conductance (Cs), transpiration rate (Tr) and net photosynthetic rate (Pn) of mulberry plantlets treated with or without ABA during the last subculture stage before ex vitro acclimatization. Each parameters were measured before and after ex vitro transfer. Means $\pm \mathrm{SE}, \mathrm{n}=20$ 
cuticle deposition on cells, sudden dehydration and increase in ROS production (Batkova et al. 2008). In vitro cultured plantlets are characterized by deficient functionality of stomata, which is gradually recovered during ex vitro acclimatization (Dias et al. 2013a, b; Hazarika 2006; Pospisilova et al. 2009b). However, ABA application strongly reduced water loss even when stomata did not function normally (Pospisilova et al. 2007), which decreased water stress during acclimatization of Ulmus minor, indicating a faster and efficient improvement of the water control mechanisms. Stomatal closure is considered as one of the first defense strategy against drought damage under water stress conditions, protecting the plants from dehydration and eventually from sudden death (Chaves et al. 2003; Dias and Bruggemann 2007). But stomatal closure unavoidably limits the $\mathrm{CO}_{2}$ availability in the intercellular spaces of the mesophyll cells. Therefore, it is very critical to find the adequate acclimatization condition to prevent water loss and enhance photosynthesis efficiency for improvement of plant ability to deal with ex vitro environmental stresses. Dias et al. (2014) reported that foliar application of ABA promoted net $\mathrm{CO}_{2}$ assimilation rate, plant dry mater accumulation and antioxidant enzyme activity. Several studies also demonstrated that $\mathrm{ABA}$ pre-treatment ameliorated negative effect of water stress in naturally grown barley, bean, maize, sugar beet and tobacco (Agarwal et al. 2005; Haisel et al. 2006; Mizrahi et al. 1974).
In our results, it was found that ABA could efficiently play a role in alleviating the negative shock from ex vitro transplantation, reducing the water loss and relieving the risk of dehydration for successful survival and vigorous growth of mulberry plantlets during acclimatization.

Effect of ABA on chlorophyll contents and its ratio during acclimatization of in vitro cultured mulberry plantlets

Figure 2 showed the chlorophyll contents and chlorophyll $a / b$ ratio of mulberry plantlets pretreated with or without ABA during ex vitro acclimatization. Significant and rapid increase of chlorophyll a content was observed in ABA-treated plantlets, of which chlorophyll $\mathrm{a}+\mathrm{b}$ content was also higher than that of control plantlets. Chlorophyll $a / b$ ratio rose considerably until 7 days after ex vitro transfer, but did not increase remarkably afterward.

Chlorophyll content is one of the most important parameters for evaluation of the plant hardening after acclimatization (Gour et al. 2007). It could be higher or lower in leaves of in vitro cultured plantlets than in corresponding ex vitro plantlets, depending on irradiance, medium composition and $\mathrm{CO}_{2}$ concentration. Exogenous ABA application increased chlorophyll a and chlorophyll $\mathrm{b}$ levels in the tomato leaf tissue (Barickman et al. 2014). Chlorophyll $\mathrm{a}+\mathrm{b}$ were higher in ABA-treated plants during ex vitro transfer of micro-

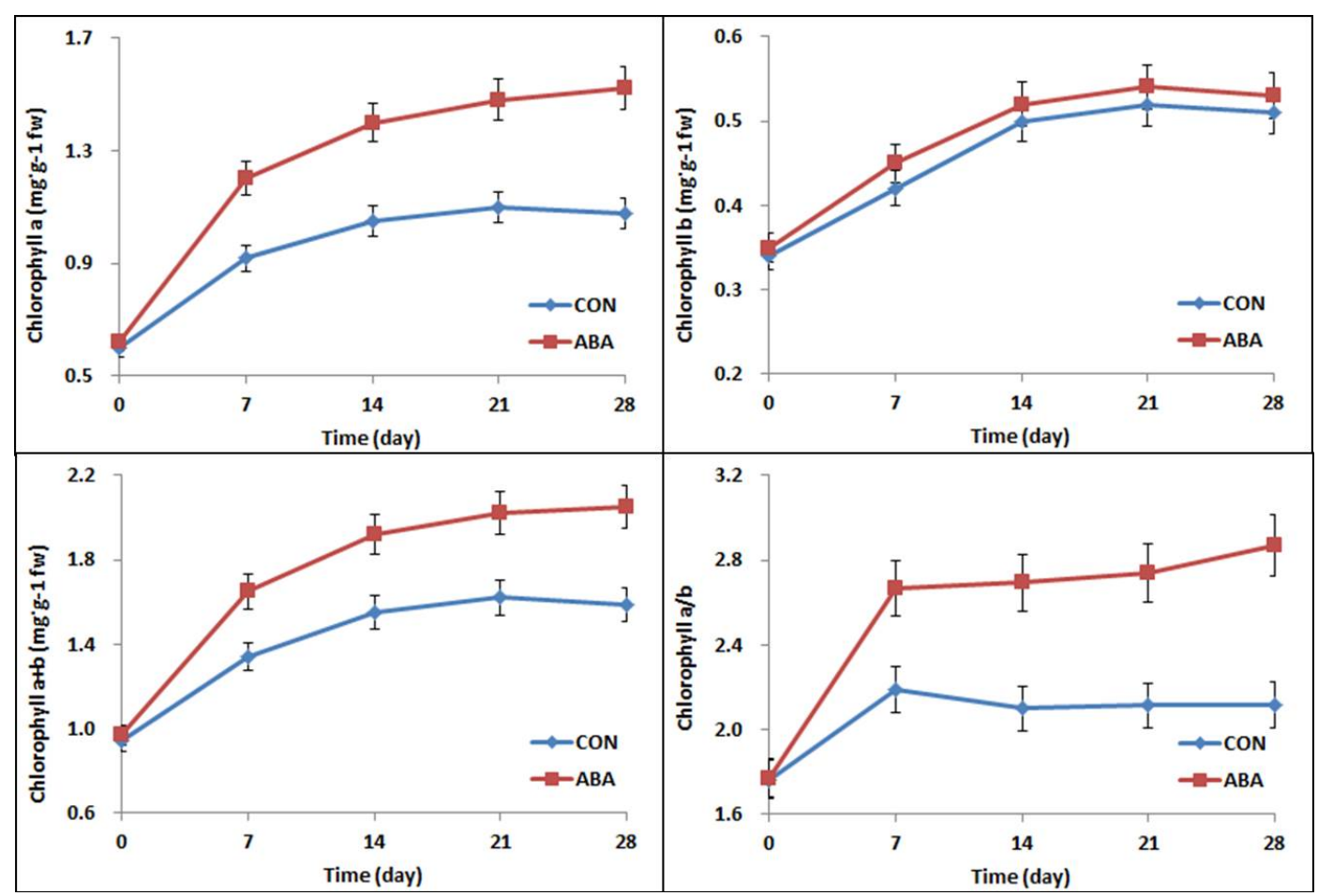

Fig. 2 Chlorophyll contents and chlorophyll $a / b$ ratio of mulberry plantlets treated with or without ABA during the last subculture stage before ex vitro acclimatization. Each parameters were measured before ex vitro transfer and after ex vitro transfer. Means \pm $\mathrm{SE}, \mathrm{n}=20$ 


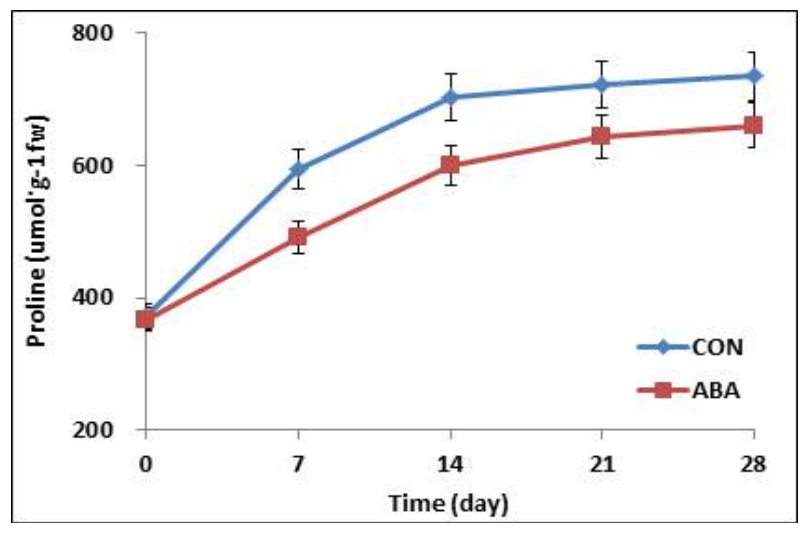

Fig. 3 Proline content of mulberry plantlets treated with or without $\mathrm{ABA}$ during the last subculture stage before ex vitro acclimatization. Each parameters were measured before ex vitro transfer and after ex vitro transfer. Means $\pm \mathrm{SE}, \mathrm{n}=20$

propagated tobacco plantlets (Pospisilova et al. 2009a). Higher chlorophyll $\mathrm{a}+\mathrm{b}$ content was also observed when $\mathrm{ABA}$ was applied immediately after ex vitro transfer (Pospisilova et al. 2009a). Chlorophyll a+b content in ABA-treated plants increased not only in persistent leaves but also new leaves developed at 2 weeks after ex vitro transfer (Pospisilova et al. 1998). In particular, increase in chlorophyll $\mathrm{a} / \mathrm{b}$ ratio induced by ABA treatment may lead to decrease in light-harvesting complex associated with photosystem II, which can help in its photoprotection (Spundova et al. 2003). Chlorophylls in leaf tissue, induced by $\mathrm{ABA}$ treatments, can increase the antioxidant capacity of plants to abiotic-induced stress (Barickman et al. 2014). Our studies also indicated that ABA application led to increase of chlorophyll contents and its ratio, which could assign high adaptability to plantlets under unfavorable ex vitro environmental condtions.

Effect of ABA on proline content during acclimatization of in vitro cultured mulberry plantlets

Higher proline content was observed in control plantlets, which increased rapidly until 14 days after ex vitro transfer (Fig. 3).
It was supposed that reduction of water stress induced by ABA pretreatment could alleviate the risk of plant dehydration and promote plant survival, resulting in decrease in proline accumulation. In addition, it was found that proline could be an indicator showing plant stress levels after ex vitro transfer, and its rapid accumulation also meant a severe water stress conditions of plants during acclimatization.

In acclimatization, several metabolic changes can be activated in an attempt to neutralize the damages caused by hydric stress including the accumulation of different compatible solutes (Hoekstra et al. 2001; Mohammadkhani and Heidari 2008). Proline is considered as the primary accumulated metabolite in different stress conditions, which contributes to maintain the water absorptive capacity and improve the drought tolerance for plant survival and establishment (Kishor et al. 1995; Liang et al. 2013; Molinari et al. 2007). Proline accumulation may occur due to the physiological responses induced by osmotic stress in plants (Zhang et al. 2000). The increase in proline synthesis in transgenic tobacco (Nicotiana tabacum) overproducing proline by elimination of feedback inhibition of P5CS, which catalyzes the proline biosynthesis, caused higher tolerance to its hyperosmotic stress (Hong et al. 2000; Kishor et al. 1995). Carvalho et al. (2013) also demonstrated that proline could modify the expression of genes related to the plant responses to water deficit.

Effect of $\mathrm{ABA}$ on general growth characteristics after 1 month of acclimatization of in vitro cultured mulberry plantlets

General growth characteristics of mulberry plantlets was evaluated on 1 month after ex vitro transfer (Table 1), the survival rate of ABA-pretreated plantlets was $85.6 \%$, which increased by $29.1 \%$ in comparison with non-treatment $(56.5 \%)$, moreover, ABA-pretreated plantlets grew more vigorously. After 6 months, most plantlets also survived successfully (Fig. 4).

Our results showed that application of ABA to the last subculture medium might improve the adaptable capacity of mulberry plantlets to ex vitro environment during acclima-

Table 1 The general growth characteristics of mulberry plantlets pretreated with or without ABA on 1 month after ex vitro acclimatization

\begin{tabular}{|c|c|c|c|c|c|c|}
\hline \multirow[b]{2}{*}{ Treatment } & \multirow{2}{*}{$\begin{array}{l}\text { Plant } \\
\text { height } \\
(\mathrm{cm})\end{array}$} & \multirow{2}{*}{$\begin{array}{l}\text { Stem } \\
\text { diameter } \\
(\mathrm{mm})\end{array}$} & \multirow{2}{*}{$\begin{array}{c}\text { Survival } \\
\text { rate } \\
(\%)\end{array}$} & \multicolumn{3}{|c|}{ Lateral branch } \\
\hline & & & & $\begin{array}{l}\text { No. } \\
\text { (/plant) }\end{array}$ & $\begin{array}{l}\text { Length } \\
\text { (cm) }\end{array}$ & $\begin{array}{c}\text { Diameter } \\
(\mathrm{mm})\end{array}$ \\
\hline Control & $9.3 \pm 0.5^{z}$ & $3.3 \pm 0.1$ & $56.5 \pm 3.0$ & $2.6 \pm 0.2$ & $3.2 \pm 0.1$ & $2.1 \pm 0.1$ \\
\hline ABA-treatment & $10.5 \pm 0.6$ & $3.4 \pm 0.1$ & $85.6 \pm 3.6$ & $3.6 \pm 0.2$ & $3.5 \pm 0.2$ & $2.1 \pm 0.1$ \\
\hline
\end{tabular}

${ }^{\mathrm{z}}$ Each value represents the mean \pm SE. 

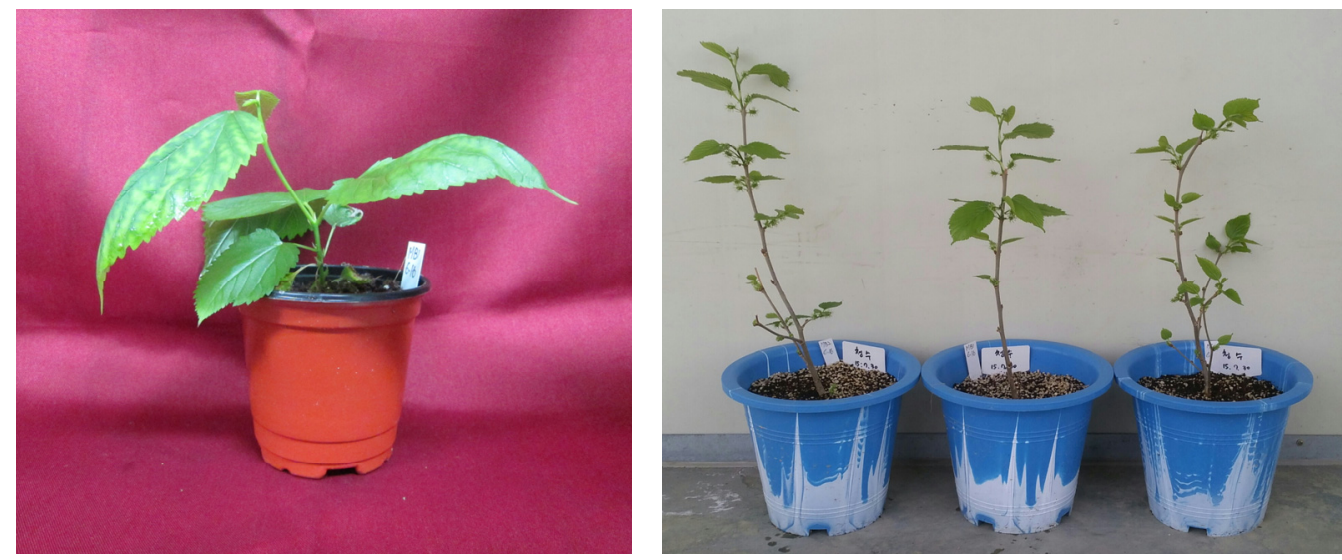

Fig. 4 Mulberry plants on 1 (left) and 6 (right) months after acclimatization and ex vitro transfer. They were pretreated with ABA during the last subculture stage before acclimatization

tization and promote more vigorous plantlet growth, due to its positive effects including the induction of stronger drought tolerance and better photoprotection.

\section{Acknowledgement}

This work was carried out with the support of Research Program for Agriculture Science \& Technology Development (PJ011085012017), Rural Development Administration, Republic of Korea.

\section{References}

Agarwal S, Sairam RK, Scrivastava GC, Meena RC(2005) Changes in antioxidant enzymes activity and oxidative stress by abscisic acid and salicylic acid in wheat genotypes. Biologia Plantarum 49:541-550

Aguilar ML, Espadas FL, Coello J, Maust BE, Trejo C, Robert ML, Santamaria JM (2000) The role of abscisic acid in controlling leaf water loss, survival and growth of micropropagated Tagetes erecta plants when transferred directly to the field. Journal of Experimental Botany 51:1861-1866

Arfan M, Khan R, Rybarczyk A, Amarowicz R (2012) Antioxidant activity of mulberry fruit extracts. International Journal of Molecular Sciences 13:2472-2480

Barickman TC, Kopsell DA, Sams CE (2014) Abscisic acid increases carotenoid and chlorophyll concentrations in leaves and fruit of two tomato genotypes. Journal of the American Society for Horticultural Science 139:261-266

Batkova P, Pospisilova J, Synkova H (2008) Production of reactive oxygen species and development of antioxidative systems during in vitro growth and ex vitro transfer. Biologia Plantarum 52:413-422

Carimi F, Zottini M, Formentin E, Terzi M, Schiavo FL (2003)
Cytokinins: new apoptotic inducers in plants. Planta 216: 413-421

Carvalho K, Campos M, Domingues D, Pereira L, Vieira L (2013). The accumulation of endogenous proline induces changes in gene expression of several antioxidant enzymes in leaves of transgenic Swingle citrumelo. Molecular Biology Reports 40:3269-3279

Chaves MM, Maroco JP, Pereira JS (2003) Understanding plant responses to drought-from genes to the whole plant. Functional Plant Biology 30:239-264

Desjardins Y, Dubuc JF, Badr A (2009) In vitro culture of plants: a stressful activity!. In III International Symposium on Acclimatization and Establishment of Micropropagated Plants 812:29-50.

Dias MC, Bruggemann W (2007) Photosynthesis under drought stress in Flaveria species with different degrees of development of the C4 syndrome. Photosynthetica 45:75-84

Dias MC, Pinto G, Correia C, Moutinho-Pereira J, Silva S, Santos C (2013a) Photosynthetic parameters of Ulmus minor plantlets affected by irradiance during acclimatization. Biologia Plantarum 57:33-40

Dias MC, Pinto G, Guerra C, Jesus C, Amaral J, Santos C (2013b) Effect of irradiance during acclimatization on content of proline and phytohormones in micropropagated Ulmus minor. Biologia Plantarum 57:769-772

Dias MC, Correia C, Moutinho-Pereira J, Oliveira H. Santos C (2014) Study of the effects of foliar application of ABA during acclimatization. Plant Cell, Tissue and Organ Culture 117: 213-224.

Gour VS, Sharma SK, Emmanuel CJSK, Kant T (2007). Stomata and chlorophyll content as marker traits for hardening of in vitro raised Balanites aegyptiaca (L.) Del. plantlets. National Academy Science Letters 30:45-47

Haisel D, Pospisilova J, Synkova H, Schnablova R. Batkova P (2006). Effects of abscisic acid or benzyladenine on pigment contents, chlorophyll fluorescence, and chloroplast ultrastructure during water stress and after rehydration. Photosynthetica 44:606-614 
Hazarika BN (2006) Morpho-physiological disorders in in vitro culture of plants. Scientia Horticulturae 108:105-120

Hetherington AM (2001) Guard Cell Signalling. Cell 107:711- 714

Hoekstra FA, Golovina EA, Buitink J (2001) Mechanisms of plant desiccation tolerance. Trends in Plant Science 6:431-438

Hong Z, Lakkineni K, Zhang Z, Verma DPS (2000) Removal of feedback inhibition of $\Delta 1$-pyrroline-5-carboxylate synthetase results in increased proline accumulation and protection of plants from osmotic stress. Plant Physiology 122:1129-1136

Hronkova M, Zahradnickova H, Simkova M, Simek P, Heydova A (2003) The role of abscisic acid in acclimation of plants cultivated in vitro to ex vitro conditions. Biologia Plantarum 46:535-541

Kelkar SM, Bapat VA, Ganapathi TR, Kaklij GS, Rao PS, Heble MR (1996) Determination of hypoglycemic activity in Morus indica L. (Mulberry) shoot culture. Current Sciences 71: 71-72

Kishor PK, Hong Z, Miao GH, Hu CAA, Verma DPS (1995) Overexpression of [delta]-pyrroline-5-carboxylate synthetase increases proline production and confers osmotolerance in transgenic plants. Plant Physiology 108:1387-1394

Koyuncu F (2004) Organic acid composition of native black mulberry fruit. Chemistry of Natural Compounds 40:367-369

Lee EJ, Bae JH (2011) Study on the alleviation of an alcohol induced hangover and the antioxidant activity by mulberry fruit. The Korean Journal of Food and Nutrition 24:204-209

Liang X, Zhang L, Natarajan SK, Becker DF (2013) Proline mechanisms of stress survival. Antioxidants and Redox Signaling 19:998-1011

Mizrahi Y, Scherings SG, Arad S, Richmond AE (1974) Aspects of the effect of ABA on the water status of barley and wheat seedlings. Physiologia Plantarum 31:44-50

Mohammadkhani N, Heidari R(2008) Drought-induced accumulation of soluble sugars and proline in two maize varieties. World Applied Science Journal 3:448-453

Molinari HBC, Marur CJ, Daros E, De Campos MKF, De Carvalho JFRP, Pereira LFP, Vieira LGE (2007) Evaluation of the stress-inducible production of proline in transgenic sugarcane (Saccharum spp.): osmotic adjustment, chlorophyll fluorescence and oxidative stress. Physiologia Plantarum 130:218-229

Pennell RI, Lamb C (1997) Programmed cell death in plants. The Plant Cell 9:1157-1168
Pospisilova J, Wilhelmova NA, Synkova H, Catsky J, Krebs D, Ticha I, Snopek J (1998) Acclimation of tobacco plantlets to ex vitro conditions as affected by application of abscisic acid. Journal of Experimental Botany 49:863-869

Pospisilova J, Ticha I, Kadlecek S, Haisel D, Pizakova S (1999) Acclimatization of micropropagated plants in ex vitro conditions. Biologia Plantarum 42:481-497

Pospisilova J, Synkova H, Haisel D, Semoradova S (2007) Acclimation of plantlets to ex vitro conditions: Effects of air humidity, irradiance, $\mathrm{CO}_{2}$ concentration and abscisic acid (a Riview). Acta Horticulturae 748.

Pospisilova J, Synkova H, Haisel D, Batkova P (2009a). Effect of abscisic acid on photosynthetic parameters during ex vitro transfer of micropropagated tobacco plantlets. Biologia Plantarum 53:11-20

Pospisilova J, Synkova H, Haisel D, Batkova P (2009b). Improvement of ex vitro transfer of tobacco plantlets by addition of abscisic acid to the last subculture. Biologia Plantarum 53:617-624

Spundova M, Popelkova H, Ilík P, Skotnica J, Novotny R, Naus J (2003) Ultrastructural and functional changes in the chloroplasts of detached barley leaves senescing under dark and light conditions. Journal of Plant Physiology 160:1051-1058

Tuteja N (2007) Abscisic acid and abiotic stress signaling. Plant Signaling and Behavior 2:135-138

Vijayan K, Srivastava PP, Raju PJ, Saratchandra B (2012) Breeding for higher productivity in mulberry. Czech Journal of Genetics and Plant Breeding 48:147-156

Wang M, Hoekstra S, van Bergen S, Lamers GE, Oppedijk BJ, van der Heijden MW, Schilperoort RA (1999) Apoptosis in developing anthers and the role of ABA in this process during androgenesis in Hordeum vulgare L. Plant Molecular Biology 39:489-501

Yen GC, Wu SC, Duh PD (1996) Extraction and identification of antioxidant components from the leaves of mulberry (Morus alba L.). Journal of Agricultural and Food Chemistry 44: 1687-1690

Zhang M, Qian J, Zheng S (2000) Studies on free proline and soluble sugar of wild soybeans (Glycine soja) under osmotic stress. Journal of Fudan University. Natural Science 40: 558-561 